\title{
Hospitalitas Kristen Dalam Konseling Pastoral
}

\author{
Stepen Untung \\ Institut Agama Kristen Negeri Toraja \\ stepenlucky@gmail.com
}

\begin{abstract}
Pastoral counseling is a conversational activity that occurs deeply reciprocally, between counselor and counselee where the counselor guides the counselee in an ideal conversation. Pastoral counseling places a counselee in an intimate relationship with God. loving touch not only gives warmth but creates a spiritual aspect in the counselee. In its implementation, it is certain that a counselor has the ability to carry out pastoral counseling. And there are attitudes that need to be applied and developed. But sometimes the problem is that the counselee is reluctant to meet with the counselor because he does not know the counselor well. So that the pastoral counseling process did not go well. So one thing that needs to be practiced is hospitality or hospitality. Although on the other hand, a counselor has the ability to approach the counselee. Hospitality itself is not just a concept of hospitality but needs to be practiced in everyday life. Hospitality itself emphasizes welcome and hospitality. The practice of Christian hospitality as a form of love as exemplified by Jesus himself. Hospitality is not only practiced by the counselor but by the counselee so that the pastoral counseling process goes well and the goals can be achieved.
\end{abstract}

Keywords: hospitality, pastoral counseling, counselor, counselee

Abstrak : Konseling pastoral adalah kegiatan percakapan yang terjadi secara timbal balik yang mendalam, antara konselor dan konseli dimana konselor membimbing konseli dalam suatu percakapan yang ideal. Konseling pastoral menempatkan seorang konseli dalam hubungan yang intim dengan Tuhan. sentuhan cinta kasih bukan hanya memberi kehangatan tetapi menimbulkan aspek spiritual dalam diri konseli. Dalam pelaksanaannya sudah pasti tentu seorang konselor memiliki kemampuan untuk pelaksaan konseling pastoral. Serta ada sikap yang perlu diterapkan dan dikembangkan. Tetapi terkadang yang menjadi persoalan adalah konseli enggan untuk bertemu dengan konselor karena belum mengenal dengan baik konselor. Sehingga proses konseling pastoral tidak berjalan dengan baik. Maka salah hal yang perlu dipraktikan adalah hospitalitas atau keramahtamahan. Meskipun disisi lain seorang konselor mempunyai kemampuan dalam melakukan pendekatan terhadap konseli. Hospitalitas sendiri bukan sekedar konsep keramahtamahan tetapi perlu praktiknya dalam kehidupan sehari-hari. Hospitalitas sendiri menekankan penyambutan dan keramahtamahan. Praktik hospitalitas Kristen sebagai wujud kasih sebagaimana yang diteladankan oleh Yesus sendiri. Hospitalitas tidak hanya dipraktikan oleh konselor tetapi oleh konseli sehingga proses konseling pastoral berjalan dengan baik dan tujuan dapat tercapai.

Kata Kunci: hospitalitas, konseling pastoral, konselor, konseli 


\section{PENDAHULUAN}

Sebagai makhluk sosial tentu manusia tidak dapat hidup sendiri, tetapi membutuhkan orang lain untuk saling membutuhkan timbal balik. ${ }^{1}$ Dalam menjalani kehidupan tentu manusia membutuhkan sesamanya dalam memenuhi kebutuhan hidupnya. Salah satu kebutuhan manusia seperti yang diungkapkan Maslow adalah kebutuhan akan kasih sayang yaitu kebutuhan akan rasa memiliki dan diterima di dalam hubungan dengan orang lain, baik hubungan terdekat itu dengan keluarga, teman sahabat dan dalam hubungan dengan yang lain. ${ }^{2}$

Salah satu kegiatan atau hal yang dimana seorang membutuhkan sesamanya ialah konseling pastoral. Konseling pastoral sendiri merupakan hubungan timbal balik antara hamba Tuhan sebagai seorang konselor dengan kliennya (konseli). Dalam hal ini konselor membimbing konselinya dalam suasana percakapan konseling yang ideal sehingga konseli mampu mengerti apa yang terjadi dan mampu melihat tujuan hidupnya dengan kekuatan dan kemampuan dari Tuhan. ${ }^{3}$ Dalam proses konseling pastoral seorang konseli yang mengalami krisis kepribadian membutuhkan perhatian dari orang lain atau dari konselor untuk, agar dapat diterima dan dikasihi sebagaimana layaknya orang hidup dalam cinta kasih yang mesra.

Dalam pelaksanaan konseling pastoral tentu ada hal yang harus diperhatikan oleh para konselor demi tercapainya tujuan dari sebuah proses konseling. Seorang konselor perlu mengembangkan beberapa sikap yaitu kasih dan penghargaan, kelemahlembutan, kerendahan hati, sabar dan tabah, bersabahat dan hangat, suka menolong, rela dan tulus, terbuka, rela berkorban dan sikap perhatian. Namun pada dasarnya terkadang ada konseli yang enggan untuk datang kepada konselor dengan alasan bahwa belum mengenal dengan baik konselor itu sehingga enggan untuk mengungkapkan masalah sehingga proses konseling tidak berjalan dengan baik. ${ }^{4}$ Oleh sebab itu perlu adanya penerapan praktik hospitalitas (keramahtamahan). Praktik hospitalitas bukan hanya diterapkan oleh seorang konselor tetapi juga oleh konseli sehingga keenggananan dapat dimanimalisir sehingga proses konseling pastoral dapat berjalan dengan baik dan tujuan dapat tercapai.

\section{TUJUAN DAN MANFAAT}

a. Tujuan penulisan

Tujuan dari penulisan ini adalah untuk memberikan sumbangsih bahwa hospitalitas dapat dipraktikan dalam berbagai hal salah satunya dalam konseling pastoral.

b. Manfaat penulisan

Dengan penulisan ini maka diharapkan dapat menambah wawasan penulis dan pembaca mengenai hospitalitas dalam konseling pastoral.

\footnotetext{
1 . J. D. Engel, Konseling Pastoral dan Isu-Isu Kontemporer (Jakarta: BPK Gunung Mulia, 2020), 1.

2. J. D. Engel, Pastoral dan Kebutuhan Dasar Konseling (Jakarta: BPK Gunung Mulia, 2020), 73

3 . Tulus Tu'u, Dasar-Dasar Konseling Pastoral (Yogyakarta: Andi, 2007), 19

4 . J. D. Engel, Pastoral dan Kebutuhan Dasar Konseling (Jakarta: BPK Gunung Mulia, 2020), 31
} 


\section{PEMBAHASAN}

Konseling pastoral merupakan pelayanan yang dilakukan dengan melawat dan mencari yang sedang mengalami pergumulan dalam kehidupannya. Hal tersebut dilakukan dengan tujuan untuk menolong mereka melalui suatu percakapan yang interaktif, timbal balik dan mendalam. ${ }^{5}$ Dalam pelaksanaan konseling pastoral terjadi percakapan tetapi percakapan dalam hal ini bukanlah sebuah percakapan yang biasa. Namun berlangsung secara timbal balik, mendalam serta terarah, spesifik karena saling memberi, mempengaruhi untuk mencari inti persoalan dan mengarah kepada sebuah solusi.

Kegiatan konseling pastoral menumbuhkan kesadaran klien agar tidak berpurapura dengan menyembunyikan kepribadian yang sebenarnya. Di dalam proses konseling pastoral pun seorang yang mengalami krisis atau masalah pasti membutuhkan perhatian dan kasih sayang dari orang lain atau seorang konselor. Perhatian dan kasih sayang membuat seseorang diterima dan dikasihi sebagai mana layaknya orang yang hidup dalam cinta dan kasih sayang yang mesra. Hal itu dapat membuat seseorang konseli untuk mengalami hubungan yang intim dengan Tuhan sehingga ia lebih bersemangat serta berjuang untuk masa depan yang lebih baik. ${ }^{6}$

Dalam sudut pandang kekristenan, pelaksanaan konseling pastoral berpolakan atau berdasarkan pada pelayanan Yesus. Dia tidak hanya memberikan layanan spiritual tetapi juga secara mental. fisik dan sosial. Bercermin kepada keteladanan Yesus maka dapat ditarik sebuah pelajaran bahwa orang sakit atau bermasalah bukan hanya pada fisik tetapi juga mental, sosial dan spiritualnya. ${ }^{7}$

\section{Sikap Yang Perlu Dikembangkan Oleh Seorang Konselor.}

Seorang konselor yang efektif tentu memiliki memiliki karakteristik dalam pelaksanaan konseling pastoral. Karakteristik itu adalah : memiliki pengetahuan konseling, pengetahuannya aplikatif atau dapat diterapkan, memiliki kepekaan. Selain itu juga ia memiliki keyakinan, memiliki kematangan yang memampukan untuk menghadapi masalah yang rumit. Menghargai konseli sebagai manusia yang unik, memiliki rasa tanggung jawab untuk menolong serta tidak mengambil alih masalah konselinya.

Selain daripada karakteristik seorang konselor yang efektif ada pula sikap yang harus dikembangkan oleh seorang konselor. Kasih dan penghargaan, kasih memungkinkan konselor untuk menolong, mengasihi dan menghargai serta memberikan pelayanan terbaik bagi konseli. Kelemahlembutan yang dapat membuat konseli merasa dihargai. Kerendahan hati, yaitu tidak menyombongkan diri dengan segala yang dimiliki. Sabar dan tabah, yang dapat membuat konselor untuk tidak putus asa. Bersahabat dan hangat, suka menolong, rela dan tulus, terbuka, rela berkorban serta sikap yang penuh perhatian. ${ }^{8}$

\footnotetext{
${ }^{5}$. Tulus Tu'u, Dasar-Dasar Konseling Pastoral (Yogyakarta: Andi, 2007), 20

6 . J. D. Engel, Konseling Pastoral dan Isu-Isu Kontemporer (Jakarta: BPK Gunung Mulia, 2020), 12

7. J. D. Engel, Konseling Pastoral dan Isu-Isu Kontemporer (Jakarta: BPK Gunung Mulia, 2020), 4-5

8 . Tulus Tu'u, Dasar-Dasar Konseling Pastoral (Yogyakarta: Andi, 2007), 44-48
} 


\section{Hospitalitas Kristen Dalam Konseling Pastoral}

Salah satu hal yang dapat mempengaruhi berjalannya proses konseling pastoral adalah komunikasi. Namun tidak jalannya komunikasi yang baik antara konselor dan konselinya maka dapat menghambat pelaksanaan konseling pastoral tersebut. Tetapi ada hal lain yang dapat mempengaruhi jalannya komunikasi serta proses konseling pastoral yaitu keengganan seorang konseli untuk datang kepada konselor. Tetapi pada dasarnya konseling pastoral proses yang dilaksanakan untuk mencari yang bergumul untuk menolong yang bergumul itu melalui percakapan yang interaktif, timbal balik dan mendasar. Melihat hal tersebut maka, salah satu hal yang perlu diterapkan adalah hospitalitas (keramahtamahan) meskipun di sisi lain tentu ada kemampuan konselor untuk mendekati konseli.

Hospitalitas secara etimologi berasal dari bahasa Yunani yaitu philoxenia yang terdiri atas philos (kasih) dan xenos (yang lain/orang asing ) yang secara harafiah dapat diartikan kasih kepada orang asing. Hospitalitas lebih dari pada suatu tindakan. Lebih dari pikiran yang dibangkitkan sekarang dan demi kebaikan kita. ${ }^{9}$ Hospitalitas merupakan cara untuk menjalin persahabatan dengan orang yang menjadi tanggung jawab setiap manusia. Hopitalitas bukanlah sekedar konsep saja tetapi perlu ada tindakan atau praktik dalam kehidupan sehari-hari dalam menjalin hubungan dengan sesama. ${ }^{10}$

Hospitalitas adalah wujud dari rasa kehangatan dalam menerima, menghormati serta persahabatan dan persaudaran terhadap orang lain. Hospitalitas Kristen merupakan hukum yang diberikan oleh Yesus sendiri yaitu hukum kasih. Yaitu kasih kepada Tuhan dan kasih kepada sesama. Pelaksanaan kasih sebagai hospitalitas Kristen merupakan suatu wujud dari seorang murid Kristus. Ada sikap yang menjadi nyawa atau dasar dari hospitalitas Kristen yaitu sikap empati. Dengan adanya empati maka seorang Kristen dapat mewujudkan kasih Kristus itu. ${ }^{11}$ Dalam hospitalitas Kristen setiap orang menyambut orang lain dengan penuh keramahan, kasih dan ketulusan tanpa harus membedakan. Hospitalitas merupakan sutu tindakan untuk menyambut orang lain dengan penuh kasih sehingga terjalin sebuah relasi persahabatan. Yang ditekankan dalam praktik hospitalitas adalah penyambutan dan keramahtamahan. ${ }^{12}$

Dari penjalasan mengenai hospitalitas maka dalam pelaksanaan konseling pastoral perlu adanya penerapan praktik hospitalitas. Hospitalitas Kristen sendiri dapat diwujudkan dalam melalui sikap empati. Empati merupakan kemampuan seseorang untuk merasakan dan memahami apa yang dialami oleh orang lain dalam konseling pastoral adalah hal apa yang dialami oleh konseli. Sehingga konselor mampu mendorong konselinya melakukan tindakan. Secara etimologi empati berasal dari

\footnotetext{
9 . Michele Hershberger, Hospitalitas: Orang Asing Teman Atau Ancaman? (Jakarta: BPK Gunung Mulia, 2009), 23

10. Yohanes K. Susanta “Hospitalitas Sebagai Upaya Mencegah Kekerasan Dan Memelihara Kerukunan Dalam Relasi Islam-Kristen Di Indonesia” Societas Dei 2, no.1 (April 2015): 281.

11 . Daniel Fajar Panuntun \& Eunike Paramita "Hospitalitas Kristen dan Tantangannya DI Tengah Pandemi Covid-19” Jurnal Multikultural \&Multireligius 19 no.1 (Oktober 2020): 67.

12 . Daniel Fajar Panuntun, 'Nilai Hospitalitas Dalam Budaya Longko' Torayan”, in Teologi Kontekstual Dan Kearifan Lokal Toraja, 2020, 19
} 
bahasa Yunani yang terdiri dari dua kata yaitu em dan phatos yang berarti bahwa perasaan yang mendalam untuk memahami dunia orang lain. Empati berbeda dengan simpati yang lebih kepada membawa perasaan seseorang pada keadaan sentimental. Empati adalah perasaan seseorang secara pribadi dapat berada dalam penderitaan atau perasaan orang tanpa harus menghilangkan perasaan sendiri. Adanya perasaan empati dalam proses konseling maka seorang konselor dapat mempunyai perasaan yang hangat dan keramahan, 13

Tentu dalam proses konseling pastoral seorang konselor memiliki kemampuan tersendiri untuk meyakinkan konselinya. Tetapi tidak terlepas juga dari hal itu maka perlu ada penerapaan hospitalitas atau keramahtamahan. Keenggaan seorang konseli untuk datang kepada konselor untuk menceritakan masalah yang dialaminya menjadi salah satu kendala dalam pelaksanaan konseling. Namun bukan berarti konselor harus berdiam diri pula sebab telah dijelaskan diatas bahwa mencari yang bergumul. Oleh sebab itu hospitalitas atau keramatamahan perlu dipraktikan.

Praktik hospitalitas bukan berarti bahwa seorang konselor mencari kehormatan sebagai seorang yang harus dihormati tetapi sebagai wujud kasih kepada sesama. Sebagaimana dalam Lukas 14, pelaksanaan praktik hospitalitas orang Farisi adalah untuk menikmati rasa hormat di depan mata para tamu mereka. ${ }^{14}$ Tuhan Yesus sendiri telah memberikan keteladanan untuk tentang praktik hospitalitas sebagai wujud kasih. Yesus tahu setiap kebutuhan setiap orang bukan dalam hal lahiriah saja tetapi sentuhan kasihnya dirasakan oleh semua orang datang kepadaNya. ${ }^{15}$

Disisi lain praktik hospitalitas juga harus dipraktikan oleh seorang konseli di dalam menerima seorang konselor yang akan membimbingnya untuk dapat menuju kepada arah yang lebih baik. Praktik hospitalitas dalam konseling pastoral harus dipraktikkan oleh konselor dan konseli. Hospitalitas Kristen sebagai wujud kasih seperti yang diajarkan oleh Yesus sendiri. Hospitalitas Kristen dapat dipraktikkan oleh konselor dan konseli dalam berbagai cara. Salah satunya adalah dengan saling menyapa satu sama lain. Sehingga dari hal ini sdapat menjalin komunikasi yang baik. Setidaknya dengan hal maka dapat memanimalisir kengganan konseli untuk datang kepada konselor. Sehingga proses konseling pastoral dapat berjalan dengan baik serta tujuannya dapat tercapai.

Praktik hospitalitas tentu akan menimbulkan resiko yaitu penyalagunaan keramahtamahan/kebaikan yang diberikan oleh tuan rumah. Tetapi hal tersebut dapat diselesaikan atau dipecahkan dengan terus menerus melakukan praktik hospitalitas hingga tercapai sebuah harmoni sehingga tidak ada saling curiga. Hospitalitas Kristen terus dilaksanakan karena tentu sebagai manusia akan saling membutuhkan dalam setiap kehidupan. ${ }^{16}$

\footnotetext{
${ }^{13}$. J. D. Engel, Pastoral dan Kebutuhan Dasar Konseling (Jakarta: BPK Gunung Mulia, 2020), 73

${ }^{14}$. Michele Hershberger, Hospitalitas: Orang Asing Teman Atau Ancaman? (Jakarta: BPK Gunung Mulia, 2009), 132

15 . J. D. Engel, Konseling Pastoral dan Isu-Isu Kontemporer (Jakarta: BPK Gunung Mulia, 2020), 5

16 . Daniel Fajar Panuntun, 'Nilai Hospitalitas Dalam Budaya Longko' Torayan”, in Teologi Kontekstual Dan Kearifan Lokal Toraja, 2020, 19
} 


\section{KESIMPULAN}

Praktik hospitalitas yang menekankan keramahtamahan dan penyambutan untuk menjalin persahabatan Hospitalitas Kristen sebagai wujud dari kasih yang ditunjukkan oleh Yesus. Praktik hospitalitas dalam konseling pastoral harus diterapakan oleh konselor dan konseli. Meskipun dalam prose konseling pastoral ada kemampuan tersendiri dari seorang konselor untuk menjalankan. Dengan adanya praktik hospitalitas, tidak ada keengganan dari konseli untuk datang kepada konselor sehingga proses konseling pastoral dapat berjalan dengan baik. Dan tujuan dari konselig pastoral bisa tercapai. Praktik hospitalitas sebagai wujud empati kepada sesama. Meskipun bahwa praktik hospitalitas akan memunculkan resiko.

\section{REFERENSI}

Engel, J. D. Pastoral dan Kebutuhan Dasar Konseling. Jakarta: BPK Gunung Mulia, 2020.

Engel, J.D. Konseling Pastoral dan Isu-Isu Kontemporer. Jakarta: BPK Gunung Mulia, 2020. Hershberger, Michele. Hospitalitas: Orang Asing Teman Atau Ancaman?. Jakarta: BPK Gunung Mulia, 2009.

Panuntun, Daniel Fajar. "Nilai Hospitalitas Dalam Budaya Longko' Torayan”, in Teologi Kontekstual Dan Kearifan Lokal Toraja, 2020, 19.

Panuntun, Daniel Fajar \& Eunike Paramita. “ Hospitalitas Kristen Dan Tantangannya Di Tengah Pandemi Covid-19", Jurnal Multikultural \&Multireligius 19 no.1 (Oktober 2020): 67-84.

Susanta, Yohanes K. "Hospitalitas Sebagai Upaya Mencegah Kekerasan Dan Memelihara Kerukunan Dalam Relasi Islam-Kristen Di Indonesia” Societas Dei 2, no.1 (April 2015): 281-312.

Tu’u, Tulus. Dasar-Dasar Konseling Pastoral. Yogyakarta: Andi, 2007. 